\title{
Impact of $g$-Load Shift on Temporal Expression Pattern of Apoptosis-linked Proteins in the Rat Mammary Gland
}

Kibrom M. Alula ${ }^{1}$, James H. Resau², Osman V. Patel ${ }^{1}$

${ }^{1}$ Department of Cell and Molecular Biology, Grand Valley State University, Allendale, MI 49401; ${ }^{2}$ BioSpecimen Science, Van Andel Institute, Grand Rapids, MI 49503

Abstract

Alteration in gravitational load impacts homeorhetic response in rat dams which affects neonatal pup survival. However, the effects of hypergravity (HG) exposure on the abundance of apoptosis-associated proteins in mammary epithelial cells (MECs) have not been characterized. Therefore, we examined whether chronic exposure to HG from midpregnancy alters the abundance of proapoptotic proteins in MECs during the late pregnancy and early lactation. A group of pregnant Sprague Dawley rats were exposed to either HG (2g) or normo-gravity (1g: stationary control [SC]) from days 11 to 20 of gestation (G20). Another set of animals were investigated from day 11 of pregnancy through days 1 and 3 (P1 and P3, respectively) postpartum. Quantitative (pixels [px]/lobule) immunohistochemistry at G20 of Cleaved Caspase-3 (CC-3), Tumor Protein p53 (P53), and vitamin D receptor (VDR) revealed that all the three proteins were increased $(p<0.01)$ in HG rats compared to SC animals. At P1, the HG group had twofold higher $(p<0.001)$ expression of $C C-3$ relative to the SC group. Approximately, 50\% ( $p<0.001)$ more VDR was detected in the HG cohorts than SC at $P 3$. These results suggest that a shift in g-load upregulates the expression of key proapoptotic proteins during the pregnancy-to-lactation transition in the rat MECs.

Keywords

Rat • Mammary Gland • Gravity • Apoptosis • Lactation • Pregnancy •Immunohistochemistry

\section{INTRODUCTION}

Cellular proliferation and apoptosis are evolutionary conserved mechanisms vital for coordinating growth at both organ and tissue levels. Critically, the coordinated regulation of cell proliferation and apoptosis is pivotal to preserving organismal homeostasis (Liebermann et al., 1995; Streichan et al., 2014). Therefore, any dysregulation in cellular turnover kinetics impacts organ differentiation and function and sequentially predisposes these organs/organ systems to pathology or failure (Davis and Ryan, 1998; Edelblum et al., 2006; Goilav, 2011; Werneck-Silva et al., 2006). For example, decreased apoptotic rates play a critical role in carcinogenesis, treatment response, and resistance development (Housman et al., 2014; Mattern and Volm, 2004). However, increased apoptotic rates are known to precipitate an array of neurodegenerative and autoimmune diseases (Kermer et al., 2004; Mattson, 2000). Similarly, the intricate synchronization of programmed cell death is pivotal in regulating key reproductive processes from ovulation to implantation (Boeddeker and Hess, 2015; Harada et al., 2004; Shikone et al., 1997). It is well established that there is an extensive turnover of the secretory cells in the mammary gland during lactogenesis and the milk output is directly correlated with the number of functional cells (Capuco and Ellis, 2013; Capuco et al., 2001; Knight and Peaker, 1982a; Li et al., 1999). Consequently, an imbalance in the cell turnover rate in the mammary gland during a lactation cycle directly impacts milk production and overall yield (Capuco and Ellis, 2013; Capuco et al., 2001; Knight and Peaker, 1982a; Li et al., 1999). However, the most significant growth and differentiation of the secretory lobuloalveolar units as well as the ductal system takes place during pregnancy (Oakes et al., 2006).

Human exploration of the lower orbit over the past five decades has revealed an array of physiological perturbations triggered by changes in the inertial environment. The physiological aberrations range from reduced trabecular architecture of cancellous bones (Grimm et al., 2016; Sibonga, 2013) to postflight orthostatic intolerance (Blaber et al., 2013). These documented physiological differences are evidently stemming from aberrations induced at the cellular/molecular level by these $g$-load shifts. In addition, research has shown that changes in inertial force lead to dysregulation of the cellular proliferation and apoptosis equilibrium (Blaber et al., 2013; Hauschild et al., 2014; Maier et al., 2015b). Although, the myriad of physiological effects has been known for decades, remarkable increase in knowledge on the consequences of $g$-load shift at cellular and

${ }^{\dagger}$ Corresponding author: Osman V. Patel

E-mail: patelo@gvsu.edu 
molecular levels utilizing model organisms holds promise to understand an array of physiological perturbations and aid in the development of effective countermeasure to pave the way for human exploration beyond the lower earth orbit.

Our previous studies on hypergravity (HG)-exposed pregnant rodents revealed increased neonatal mortality and decreased lipogenesis in the mammary gland (Casey et al., 2012; Patel et al., 2008). In addition, we found that genes encoding rate-limiting metabolic enzymes were downregulated in the mammary gland (Patel et al., 2007; Patel et al., 2008). Later, our transcriptome studies of animals exposed to both hypoand hyper-gravity showed that changes in the inertial force affected steady-state expression of transcripts regulating circadian rhythm, post-synthetic DNA modification, and cellular mechano-transduction (Casey et al., 2015). Our recent investigation employing spectral-based quantitative immunohistochemistry demonstrated that the composition of cytoskeletal proteins in the pregnant and lactating mammary glands was altered with the g-load shift (Alula et al., 2018). However, there are no data on the effects of altered gravity on the expression dynamics of proapoptotic proteins during the pregnancy-to-lactation transition in a mammary gland of an experimental animal model. Therefore, in the present investigation, we extended our preceding study to quantify the temporal distribution of apoptosis-related proteins, namely Cleaved Caspase-3 (CC-3), Tumor Protein p53 (p53), and vitamin $\mathrm{D}$ receptor (VDR) in the mammary tissue harvested from rats exposed to $H G$ during the periparturient period employing quantitative immunohistochemistry.

\section{METHODS}

\section{Animals and Treatment Condition}

The research approval, experimental setup, and specimen collection from the animals are detailed in our previous studies (Alula et al., 2018). Briefly, 24 time-bred weightmatched Sprague Dawley rats were randomly assigned to either experimental $(n=12)$ or control $(n=12)$ conditions. Next, the experimental $(\mathrm{HG})$ rats were allocated into the following three groups ( $n=4$ per group): group 1 animals were monitored on the NASA Ames Research Center's 24-ft centrifuge $(2 \mathrm{~g})$ from days 11 to 20 of pregnancy (G20), group 2 rats were monitored on the centrifuge from day 11 of pregnancy to postpartum (lactation) day 1 (P1), and group 3 experienced the $2 g$ force from day 11 of pregnancy to postpartum day 3 (P3). The corresponding (G20; P1; P3) stationary control (SC) groups ( $n=4$ per group) were exposed to $1 \mathrm{~g}$ for the same duration of time as their experimental counterparts while maintained under the same environmental conditions (light, sound, temperature, and humidity) as the experimental group. Real-time videography was used to record the dams' labor and delivery. $\mathrm{HG}$ and SC dams were euthanized at the designated experimental time points (G20; P1; P3) prior to mammary gland tissue collection.

\section{Immunohistochemistry}

The procedures for specimen preparation, immunohistochemistry optimization, and antibody validation are same as detailed in our recent study (Alula et al., 2018). Briefly, we used Ventana's automated staining system (Discovery XT; Ventana Medical Systems, Tucson, AZ) to process and stain the slides. The primary antibodies utilized were mouse monoclonal anti-p53 (CS2524; Cell signaling Technology, Danvers, MA), rabbit polyclonal anti-CC-3 (CS9661; Cell signaling Technology, Danvers, MA), and rabbit polyclonal anti-VDR (SC-1009, Santa Cruz Biotechnology, Santa Cruz, CA). Bound antibodies were visualized using anti-mouse/anti-rabbit multimers (horseradish peroxidase [diaminobenzidine], alkaline phosphatase [liquid permanent red]; Ventana Medical Systems, Tucson, AZ). Each slide was counterstained with hematoxylin.

\section{Imaging and Antigen Quantification}

The same approach detailed recently (Alula et al., 2018) was utilized to acquire digital micrographs from each group using a Brightfield (Nikon Eclipse 80i, Nikon Corporation, Japan) microscope. Thereafter, the signal intensities of CC3 , p53, and VDR were quantified employing the CRi Nuance Multispectral Imaging System (Caliper Life Sciences, MA) as described (Fiore et al., 2012; Huang et al., 2013). The ability of the Nuance spectral library to unmix ( $n=3-7$ lobules/ micrograph; 4 micrographs/slide) the target antigen from the counterstain within the area of interest (lobule) permitted the quantification of signal intensity per unit of DNA staining (pixels [px]) as shown in Figure 1.

\section{Statistical Analysis}

Statistical analyses within (HG and SC: $G 20$ vs P1; G20 vs P3; $P 1$ vs $P 3$ stages) a group and between ( $H G$ vs $S C$ within $G 20$; P1; P3) groups were done using Student's t-test (GraphPad Prism $^{\circledast}$ 6.07). Data are expressed as mean \pm standard error of the mean (SEM), and $p<0.05$ was considered as significant (levels of statistical significance are denoted by asterisks in the graphs).

\section{RESULTS}

In this study, we characterized the temporal expression profiles of CC-3, p53, and VDR proteins across the physiological stages of pregnancy and lactation under increased $g$-load. Broadly, the alteration of $g$-load influences the abundance of 


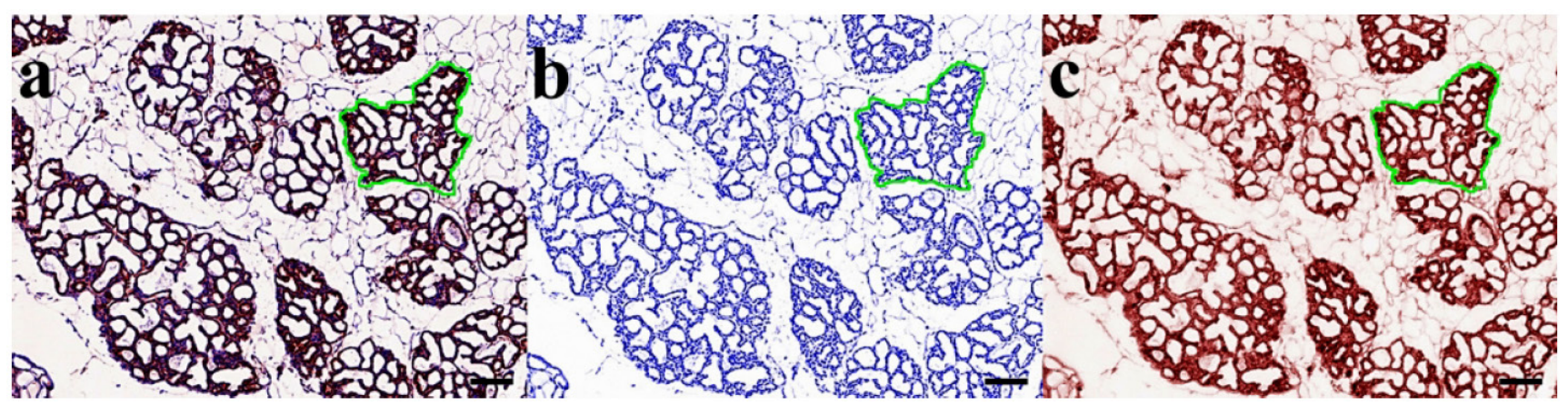

Figure 1. Representative images of lobular outlining (green) and unmixing for protein quantification. An overlay image (a) was unmixed into blue hematoxylin (b) and red VDR (c). The unmixed images of dual-labeled slide enable quantification of individual, as well as overlapping signals within the same outlined lobular border. The scale bar represents $50 \mathrm{~mm}$ (10x magnification) in the photomicrographs. VDR, vitamin D receptor.

these proapoptotic proteins during the pregnancy-to-lactation transition in the mammary gland.

\section{Effect of HG on Temporal Distribution of CC-3 Protein} The time-related quantitative mammary gland lobular expression of CC-3 antigen in both groups of animals is shown in Figure $2 \mathrm{a}$ and $\mathrm{b}$. In the SC group, the abundance of $\mathrm{CC}-3$ at P1 $(0.038 \pm 0.003 \mathrm{px})$ decreased by about $20 \%(\mathrm{p}<0.05)$ compared to $\mathrm{G} 20(0.050 \pm 0.003 \mathrm{px})$ accumulation (Fig. 2a). However, at P3 $(0.056 \pm 0.003 \mathrm{px})$, the amount of CC-3 in the SC rats had increased to parallel the concentrations detected at G20. On the contrary, no difference was detected in CC-3 levels between G20 $(0.079 \pm 0.003 \mathrm{px})$ and P1 (0.081 $\pm 0.004 \mathrm{px})$ in the HG-exposed animals (Fig. 2a). Thereafter, there was an approximately $30 \%(p<0.001)$ drop in CC-3 accumulation in the HG group at P3 $(0.055 \pm 0.005$ px). Stage-related comparisons between the SC and HG groups showed that the HG rats expressed about $40 \%$ more $(p<0.001)$ CC-3 proteins at $\mathrm{G} 20$ and $\mathrm{P} 1$ stages compared to their corresponding SC animals (Fig. 2b).

\section{Effect of HG on Temporal Distribution of Tumor Protein p53}

The comparative stage-specific mammary gland lobular quantitative profiles of $p 53$ protein between $S C$ and $H G$ animals are demonstrated in Figure $2 \mathrm{c}$ and d. A $20 \%$ $(p<0.001)$ reduction in $p 53$ expression levels during the transition from $\mathrm{G} 20(2.19 \pm 0.070 \mathrm{px})$ to $\mathrm{P} 1(1.72 \pm 0.069 \mathrm{px})$ was observed in the SC group. Thereafter, the p53 amounts increased $(p<0.001)$ by over twofolds $(4.04 \pm 0.11 \mathrm{px})$ at $P 3$ compared to $\mathrm{P} 1$ concentrations in SC rats (Fig. 2c). The time-related p53 abundance in the HG group paralleled that of SC cohorts, except the HG $(2.45 \pm 0.05 \mathrm{px})$ rats that had a higher $(p<0.05)$ level of $p 53$ at $G 20$ versus SC animals (Fig. 2d).

\section{Effect of HG on Temporal Distribution of VDR Protein} The time-trend quantitative profile of mammary gland lobular VDR in SC and HG rats is depicted in Figure 2e and f. VDR protein concentration declined by about $50 \%(p<0.001)$ in SC animals during the transition from G20 $(3.6 \pm 0.24 \mathrm{px})$ to P1 (1.8 $\pm 0.05 p x)$. Subsequently, the VDR levels increased approximately fivefold $(p<0.001)$ at P3 $(10.8 \pm 0.52 \mathrm{px})$ versus $\mathrm{P} 1$ levels in the $\mathrm{SC}$ group (Fig. 2e). On the other hand, the HG-G20 $(7.03 \pm 0.28 \mathrm{px})$ rats had about $300 \%$ $(p<0.001)$ more VDR expressed than their P1 $(2.09 \pm 0.11 p x)$ counterparts. Thereafter, the quantity of VDR protein surged by about eightfold $(p<0.001)$ in this group at P3 $(16.2 \pm 1.45$ px), compared to their P1 levels (Fig. 2e). Time-related comparisons between treatment groups showed that the $H G$ rats expressed almost twofold more VDR protein at G20 $(p<0.001)$ and about $50 \%$ higher at P3 $(p<0.001)$ in relation to the corresponding SC cohorts (Fig. 2f).

\section{DISCUSSION}

The biological phenomenon of apoptosis is indispensable for organ sculpting and tissue homeostasis. Therefore, any alteration to the intricate signaling pathway of a physiologically regulated death process likely triggers a variation in organ function and organismal physiological equilibrium (Liebermann et al., 1995; Streichan et al., 2014). Several earlier studies have already shown the impact of altered gravity on an array of apoptotic signals (Blaber et al., 2013; Grimm et al., 2016; Hauschild et al., 2014; Maier et al., 2015a; Sibonga, 2013). However, to our knowledge, there is no description of an effect of $g$-load shift on the quantitative abundance of key apoptotic effectors in a unique organ that markedly expands and functionally differentiates during the key postnatal stages of pregnancy and lactation in mammals. 


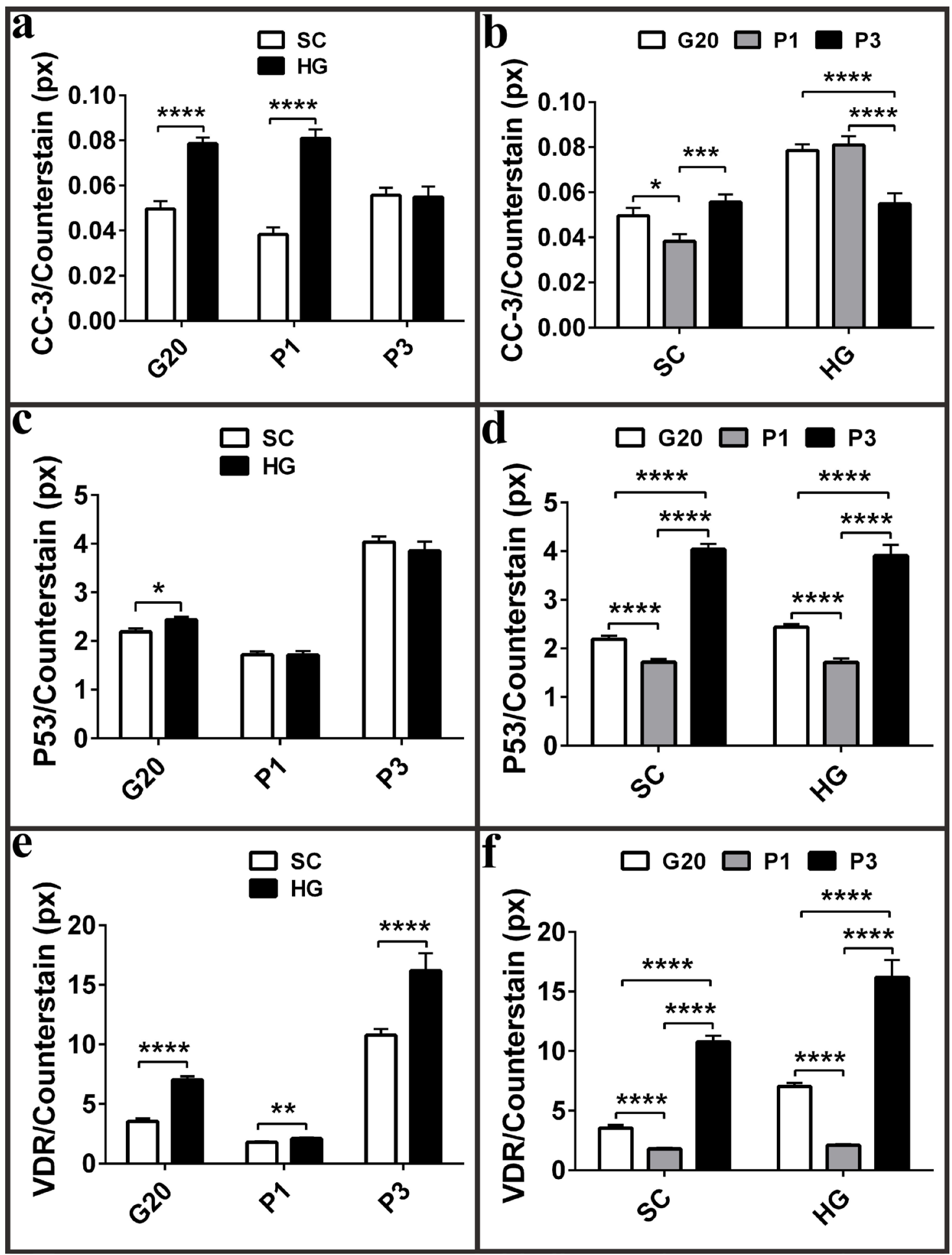

Figure 2. Quantitative comparison of mammary gland lobular CC-3 (a: within groups; b: between groups), P53 (c: within groups; d: between groups), and VDR (e: within groups; f: between groups) proteins measured in SC and HG-exposed rats following unmixing of chromophores using the CRi Nuance Multispectral Imaging System at G20, P1, and P3. Data are shown as mean \pm SEM; "significantly different within and between each group $\left({ }^{*} p<0.05 ;{ }^{* *} p<0.005 ;{ }^{* * *} p<0.001 ;{ }^{* * * *} p<0.0001\right)$.

G20, day 20 of gestation; HG, hypergravity; P1, postpartum day 1; P3, postpartum day 3; P53, tumor protein p53; SC, stationary control; SEM, standard error of the mean; VDR, vitamin D receptor 
The Caspase family of cysteine proteases plays a crucial role in the downstream signaling and execution of the cell death pathway (Barman et al., 2018; Zimmermann et al., 2001). Among the Caspases, $\mathrm{CC}-3$ is regarded as the primary mediator of the apoptotic machinery (Barman et al., 2018; Zimmermann et al., 2001). Moreover, there is a strong correlation between CC-3 immunostaining intensity and cellular apoptosis (Arai et al., 2005; Bressenot et al., 2009). In addition, it is known that CC-3 mutant mice develop hyperplastic tissue due to the lack of apoptosis and succumb to death perinatally (Zheng et al., 1999). Consequently, we determined the abundance of CC-3 in this study and our results demonstrate that $\mathrm{CC}-3$ is overexpressed $(p<0.001)$ during mammogenesis and lactogenesis in the mammary gland of HG animals (Fig. $2 b)$. In addition, our findings further reveal that a $g$-load shift modifies the temporal expression pattern of $\mathrm{CC}-3$ in the mammary gland across the pregnancy-to-lactation continuum. Our findings are consistent with previous studies that have shown an upregulation in CC-3 expression across a variety of proliferating cells exposed to altered gravity (Hosoyama et al., 2017; Maier et al., 2015a; Meng et al., 2011; Uva et al., 2002; Wehland et al., 2013; Zanello et al., 2013). Moreover, time variable experiments utilizing in vitro models report detecting significant active cell death within a short period of exposure to simulated microgravity (Bhat et al., 2001; Meng et al., 2011; Sarkar et al., 2000; Uva et al., 2002; Yang et al., 2002). In contrast, CC-3 levels are markedly downregulated in diverse types of cancer from hematopoietic to gynecological compared to normal tissue (Estrov et al., 1998; Izban et al., 1999; Winter et al., 2001). In addition, investigators have suggested that the abundance of CC-3 aids in predicting the clinical outcome, as well as patient prognosis in a select number of neoplasia $\mathrm{Hu}$ et al., 2014; Huang et al., 2017; Pu et al., 2017). Altogether, these differences indicate the importance of distinctive and delicate spatiotemporal balance of $\mathrm{CC}-3$ expression within tissues to orchestrate and manage active cell death while maintaining homeostasis in an organism.

P53 is recognized as a custodian of a cell for its ability to recognize the irreversible DNA defects induced by physicochemical stress and synchronously limiting the regeneration of these cells through affecting apoptosis (Oren, 1999). Accordingly, its expression is tightly regulated during cellular stress, including environmental, leading to a rapid induction, stabilization, and termination of p53's elicited intracellular antiproliferative transcriptional machinery (Oren, 1999). Earlier studies found an exponential increase in cell population and limited apoptosis in the mammary gland during the mammogenesis stage (Knight and Peaker, 1982a). However, our findings show that a significant upregulation of p53 occurred in the HG cohorts during this vital stage of mammary lobuloalveolar morphogenesis and functional differentiation (Fig. 2d). Noticeably, there was no difference detected in the temporal pattern of p53 expression between control and HG rats following the onset of lactogenesis II (P1 and P3; Fig. 2d). Our findings of no disparity during early postpartum period could be associated with the limited degree of cell proliferation during the transition of the gland from nonsecretory to secretory state (Knight et al., 1984; Knight and Peaker, 1982b; Lamote et al., 2004). On the other hand, over fivefold increase in p53 expression was detected under simulated microgravity conditions in cells that are known to replicate rapidly (Lin et al., 2016; Meng et al., 2011). A recent study reported an upregulation of p53 in human fibroblasts following $3 \mathrm{~h}$ of culture at the International Space Station (Lu et al., 2017). Interestingly, identical trend of increased p53 accumulation in cancer cells under HG conditions was documented over a decade ago (Okaichi et al., 2002). Other studies (Ohnishi et al., 1996; Ohnishi et al., 1999) also demonstrated comparable findings of elevated p53 levels in the skin and muscle tissue of rodents flown in space as well as cohorts exposed to altered gravity using ground-based modules.

VDR regulates mammary gland development from puberty to lactogenesis, including during involution (Johnson et al., 2014). It intricately controls proliferation, apoptosis, and differentiation of mammary gland cells (Ching et al., 2011). Epithelial hyperplasia, impaired involution of the mammary gland, and increased susceptibility to carcinogenesis have been observed in VDR null mice due to defects in the apoptotic circuitry (Zinser and Welsh, 2004b). In addition, structural studies have established that VDR binds to the VDR response element in the promoter region and stimulates antiproliferative and proapoptotic intracellular pathways (Colston et al., 1981; Koike et al., 1997; Peehl et al., 1994). Therefore, a decline in VDR in a developing mammary gland accelerates glandular growth and reduces apoptosis leading to atypical alveologenesis (Zinser et al., 2005; Zinser and Welsh, 2004a). Our temporal profile of VDR antigen across the pregnancy-to-lactation transition in the control group is comparable to the VDR mRNA steady-state pattern identified for this stage (Zinser and Welsh, 2004a). However, to the best of our knowledge, this study is the first to describe the impact of $g$-load shift on the mammary gland temporal pattern of VDR during the pregnancy-to-lactation transition using a rodent model. We found over twofold overexpression of VDR during pregnancy and above 50\% more VDR levels during lactation in rats exposed to altered gravity. Similar alterations in VDR expression are described in femurs harvested from a hind-limb unloading experiment (Xin et al., 2015) and in bone and renal cells exposed to microgravity (Hammond et al., 2000; Narayanan et al., 2002; Xin et al., 2015). Furthermore, a correlation between osteoporosis and polymorphism of VDR genes has been identified in cosmonauts returning to earth after an extended stay on the orbital stations (Oganov et al., 2010). Interestingly, over the past decades, significant 
effort has been devoted to assessing the role of VDR in $g$-load-induced osteoporosis of the weight-bearing bones and development of an effective countermeasure (Kouhnavard et al., 2014; Smith and Heer, 2002; Smith et al., 1999; Smith et al., 2005; Tian et al., 2017). However, our results suggest that other organ systems that are VDR dependent for functional differentiation and maturation may also be correspondingly affected with $g$-load shift.

Prolactin (PRL), in synergy, with glucocorticoids is indispensable for structural development and functional differentiation of the mammary gland (Knight \& Peaker, 1982b, Capuco \& Ellis, 2013). Previous $g$-load studies associated perturbations in PRL concentration with the mammary metabolic phenotype (Megory and Oyama, 1984; Megory and Oyama, 1985). However, in our earlier studies, we neither found a correlation between $g$-load and the differentially regulated PRL receptor isoforms nor was PRL or glucocorticoid supplementation able to alleviate the HG-induced metabolic deficit (Patel et al., 2007; Patel et al., 2008). In effect, the PRL and glucocorticoid treatments further exacerbated the downregulation of cognate receptors in the mammary gland of HG-exposed animals (Patel et al., 2008). Based on our preceding findings, we did not quantify the PRL receptor isoforms or the glucocorticoid receptor in the present study. However, other studies have shown an association between PRL expression and loss of p53 in breast cancer mouse model, along with PRL preventing nuclear translocation of VDR in osteosarcoma cells (Deng et al., 2009). To date, there is no documentation in the literature of any correlation between PRL or glucocorticoids and CC-3 expression. Taken together, further studies are warranted to investigate the association between mammogenic and lactogenic hormones and the spatiotemporal distribution of proapoptotic proteins during the structural development and functional differentiation of the rat mammary gland.

To conclude, we have demonstrated that utilizing immunolocalization and spectral quantification of the key apoptotic proteins, CC-3, p53, and VDR, is upregulated in the mammary gland of rats exposed to HG during the pregnancy-tolactation transition. Our temporal apoptotic signature strongly supports the notion that the increased programmed cell death during mammogenesis and lactogenesis in rats exposed to altered gravity diminishes the overall population of secretory mammary cells leading to insufficient milk production by the dam and higher neonatal mortality. The current study adds to our earlier findings on the effect of altered $g$-load on the key metabolic organs and reproductive systems. Further work is needed to methodically dissect the extrinsic and intrinsic apoptotic molecular circuitry induced by the change in gravity vector on a developing mammary gland. The identification of $g$-load-associated apoptotic signature during mammogenesis and lactogenesis could then be utilized to develop effective countermeasures.

\section{ACKNOWLEDGMENTS}

A debt of gratitude is owed to Dr. Karen Plaut (Purdue University) and her collaborators for sharing tissue collected through their NASA grant NNA05CP91A. Appreciation is also extended to Bree Berghuis, Kristen Feenstra, and Eric Hudson of Van Andel Institute for their expert help with immunohistochemistry and image analysis.

\section{Conflict of interest}

No conflicts of interest, financial or otherwise, are declared by the authors.

\section{References}

Alula KM, Resau JH, Patel OV (2018) Chronic exposure to altered gravity during the pregnancy-to-lactation transition affects abundance of cytoskeletal proteins in the rat mammary gland. Gravitational and Space Research 6, 58-72.

Arai M, Sasaki A, Saito N, Nakazato Y (2005) Immunohistochemical analysis of cleaved caspase-3 detects high level of apoptosis frequently in diffuse large B-cell lymphomas of the central nervous system. Pathology International 55, 122-129.

Barman J, Kumar R, Saha G, Tiwari K, Dubey VK (2018) Apoptosis: Mediator molecules, interplay with other cell death processes and therapeutic potentials. Current Pharmaceutical Biotechnology 19, 644-663.

Bhat GK, Yang H, Sridaran R (2001) Simulated conditions of microgravity suppress progesterone production by luteal cells of the pregnant rat. Journal of Gravitational Physiology 8, 57-66.

Blaber AP, Zuj KA, Goswami N (2013) Cerebrovascular autoregulation: Lessons learned from spaceflight research. European Journal of Applied Physiology 113, 1909-1917.

Boeddeker SJ, Hess AP (2015) The role of apoptosis in human embryo implantation. Journal of Reproductive Immunology 108, 114-122.

Bressenot A, Marchal S, Bezdetnaya L, Garrier J, Guillemin F, Plenat F (2009) Assessment of apoptosis by immunohistochemistry to active caspase-3, active caspase-7, or cleaved PARP in monolayer cells and spheroid and subcutaneous xenografts of human carcinoma. Journal of Histochemistry and Cytochemistry 57, 289-300

Capuco AV, Ellis SE (2013) Comparative aspects of mammary gland development and homeostasis. Annual Review of Animal Biosciences 1, 179-202.

Capuco AV, Wood DL, Baldwin R, McLeod K, Paape MJ (2001) Mammary cell number, proliferation, and apoptosis during a bovine lactation: Relation to milk production and effect of bST. Journal of Dairy Sciences 84, 2177-2187. 
Casey T, Patel OV, Plaut K (2015) Transcriptomes reveal alterations in gravity impact circadian clocks and activate mechanotransduction pathways with adaptation through epigenetic change. Physiological Genomics 47, 113-128.

Casey T, Zakrzewska El, Maple RL, Lintault L, Wade CE, Baer LA, Ronca AE, Plaut K (2012) Hypergravity disruption of homeorhetic adaptations to lactation in rat dams include changes in circadian clocks. Biology Open 1, 570-581.

Ching S, Kashinkunti S, Niehaus MD, Zinser GM (2011) Mammary adipocytes bioactivate 25-hydroxyvitamin $\mathrm{D}(3)$ and signal via vitamin $\mathrm{D}(3)$ receptor, modulating mammary epithelial cell growth. Journal of Cellular Biochemistry 112, 3393-3405.

Colston K, Colston MJ, Feldman D (1981) 1,25-dihydroxyvitamin D3 and malignant melanoma: The presence of receptors and inhibition of cell growth in culture. Endocrinology 108, 1083-1086.

Davis MA, Ryan DH (1998) Apoptosis in the kidney. Toxicologic Pathology 26, 810-825.

Deng C, Ueda E, Chen KE, Bula C, Norman AW, Luben RA, Walker AM (2009) Prolactin blocks nuclear translocation of VDR by regulating its interaction with BRCA1 in osteosarcoma cells. Molecular Endocrinology 23, 226-236.

Edelblum KL, Yan F, Yamaoka T, Polk DB (2006) Regulation of apoptosis during homeostasis and disease in the intestinal epithelium. Inflammatory Bowel Disease 12, 413-424.

Estrov Z, Thall PF, Talpaz M, Estey EH, Kantarjian HM, Andreeff M, Harris D, Van Q, Walterscheid M, Kornblau SM (1998) Caspase 2 and caspase 3 protein levels as predictors of survival in acute myelogenous leukemia. Blood 92, 3090-3097.

Fiore C, Bailey D, Conlon N, Wu X, Martin N, Fiorentino M, Finn S, Fall K, Andersson SO, Andren O, Loda M, Flavin R (2012) Utility of multispectral imaging in automated quantitative scoring of immunohistochemistry. Journal of Clinical Pathology 65 , 496-502.

Goilav B (2011) Apoptosis in polycystic kidney disease. Biochimica et Biophysica Acta 1812, 1272-1280.

Grimm D, Grosse J, Wehland M, Mann V, Reseland JE, Sundaresan A, Corydon TJ (2016) The impact of microgravity on bone in humans. Bone 87, 44-56.

Hammond TG, Benes E, O'Reilly KC, Wolf DA, Linnehan RM, Taher A, Kaysen JH, Allen PL, Goodwin TJ (2000) Mechanical culture conditions effect gene expression: Gravity-induced changes on the space shuttle. Physiological Genomics 3, 163-173.

Harada T, Kaponis A, Iwabe T, Taniguchi F, Makrydimas G, Sofikitis N, Paschopoulos M, Paraskevaidis E, Terakawa N (2004) Apoptosis in human endometrium and endometriosis. Human Reproduction Update 10, 29-38.

Hauschild S, Tauber S, Lauber B, Thiel CS, Layer LE, Ullrich O (2014) T cell regulation in microgravity - The current knowledge from in vitro experiments conducted in space, parabolic flights and ground-based facilities. Acta Astronautica 104, 365-377.

Hosoyama T, Ichida S, Kanno M, Ishihara R, Hatashima T, Ueno K, Hamano K (2017) Microgravity influences maintenance of the human muscle stem/progenitor cell pool. Biochemical and Biophysical Research Communications 493, 998-1003.

Housman G, Byler S, Heerboth S, Lapinska K, Longacre M, Snyder N, Sarkar S (2014) Drug resistance in cancer: An overview. Cancers (Basel) 6, 1769-1792.

Hu Q, Peng J, Liu W, He X, Cui L, Chen X, Yang M, Liu H, Liu S, Wang $H$ (2014) Elevated cleaved caspase-3 is associated with shortened overall survival in several cancer types. International Journal of Clinical and Experimental Pathology 7, 5057-5070.

Huang JS, Yang CM, Wang JS, Liou HH, Hsieh IC, Li GC, Huang SJ, Shu CW, Fu TY, Lin YC, Ger LP, Liu PF (2017) Caspase-3 expression in tumorigenesis and prognosis of buccal mucosa squamous cell carcinoma. Oncotarget 8, 84237-84247.

Huang W, Hennrick K, Drew S (2013) A colorful future of quantitative pathology: Validation of Vectra technology using chromogenic multiplexed immunohistochemistry and prostate tissue microarrays. Human Pathology 44, 29-38.

Izban KF, Wrone-Smith T, Hsi ED, Schnitzer B, Quevedo ME, Alkan $S$ (1999) Characterization of the interleukin-1beta-converting enzyme/ced-3-family protease, caspase-3/CPP32, in Hodgkin's disease: Lack of caspase-3 expression in nodular lymphocyte predominance Hodgkin's disease. The American Journal of Pathology 154, 1439-1447.

Johnson AL, Zinser GM, Waltz SE (2014) Loss of vitamin D receptor signaling from the mammary epithelium or adipose tissue alters pubertal glandular development. American Journal of PhysiologyEndocrinology and Metabolism 307, E674-E685.

Kermer P, Liman J, Weishaupt JH, Bahr M (2004) Neuronal apoptosis in neurodegenerative diseases: From basic research to clinical application. Neurodegenerative Diseases 1, 9-19.

Knight $\mathrm{CH}$, Docherty AH, Peaker M (1984) Milk yield in rats in relation to activity and size of the mammary secretory cell population. Journal of Dairy Research 51, 29-35.

Knight CH, Peaker M (1982a) Effects of fasting during mid pregnancy or early lactation on mammary development and milk yield in mice. Journal of Dairy Research 49, 567-575.

Knight $\mathrm{CH}$, Peaker M (1982b) Mammary cell proliferation in mice during pregnancy and lactation in relation to milk yield. Quarterly Journal of Experimental Physiology 67, 165-177.

Koike M, Elstner E, Campbell MJ, Asou H, Uskokovic M, Tsuruoka N, Koeffler HP (1997) 19-nor-hexafluoride analogue of vitamin D3: A novel class of potent inhibitors of proliferation of human breast cell lines. Cancer Research 57, 4545-4550.

Kouhnavard M, Nasli Esfahani E, Montazeri M, Hashemian SJ, Mehrazma M, Larijani B, Nezami Asl A, Khoshvaghti A, Falsafi A, Lalehfar K, Malekpour K, Vosugh M (2014) Effects of vitamin D and calcium supplementation on micro-architectural and densitometric changes of rat femur in a microgravity simulator model. Iranian Red Crescent Medical Journal 16, e18026.

Lamote I, Meyer E, Massart-Leen AM, Burvenich C (2004) Sex steroids and growth factors in the regulation of mammary gland proliferation, differentiation, and involution. Steroids 69, 145-159. 
Li P, Rudland PS, Fernig DG, Finch LM, Wilde CJ (1999) Modulation of mammary development and programmed cell death by the frequency of milk removal in lactating goats. The Journal of Physiology 519 Pt 3, 885-900.

Liebermann DA, Hoffman B, Steinman RA (1995) Molecular controls of growth arrest and apoptosis: p53-dependent and independent pathways. Oncogene 11, 199-210.

Lin SC, Gou GH, Hsia CW, Ho CW, Huang KL, Wu YF, Lee SY, Chen YH (2016) Simulated microgravity disrupts cytoskeleton organization and increases apoptosis of rat neural crest stem cells via upregulating CXCR4 expression and RhoA-ROCK1-p38 MAPK-p53 signaling. Stem Cells and Development 25, 1172-1193.

Lu T, Zhang Y, Kidane Y, Feiveson A, Stodieck L, Karouia F, Ramesh G, Rohde L, Wu H (2017) Cellular responses and gene expression profile changes due to bleomycin-induced DNA damage in human fibroblasts in space. PLoS One 12, e0170358.

Maier JA, Cialdai F, Monici M, Morbidelli L (2015a) The impact of microgravity and hypergravity on endothelial cells. Biomed Research International 2015, 434803.

Maier JA, Cialdai F, Monici M, Morbidelli L (2015b) The impact of microgravity and hypergravity on endothelial cells. Biomed Research International 2015, 434803.

Mattern J, Volm M (2004) Imbalance of cell proliferation and apoptosis during progression of lung carcinomas. Anticancer Research $\mathbf{2 4}$ 4243-4246.

Mattson MP (2000) Apoptosis in neurodegenerative disorders. Nature Reviews Molecular Cell Biology 1, 120-129.

Megory E, Oyama J (1984) Hypergravity effects on litter size, nursing activity, prolactin, TSH, T3, and T4 in the rat. Aviation, Space, and Environmental Medicine 55, 1129-1135.

Megory E, Oyama J (1985) Intrauterine fetal response to hypergravity by reduction of plasma prolactin levels in the rat. American Journal of Obstetrics \& Gynecology 153, 811-812.

Meng R, Xu HY, Di SM, Shi DY, Qian AR, Wang JF, Shang P (2011) Human mesenchymal stem cells are sensitive to abnormal gravity and exhibit classic apoptotic features. Acta Biochimica et Biophysica Sinica (Shanghai) 43, 133-142.

Narayanan R, Smith CL, Weigel NL (2002) Vector-averaged gravityinduced changes in cell signaling and vitamin $D$ receptor activity in MG-63 cells are reversed by a 1,25-(OH)2D3 analog, EB1089. Bone 31, 381-388.

Oakes SR, Hilton HN, Ormandy CJ (2006) The alveolar switch: Coordinating the proliferative cues and cell fate decisions that drive the formation of lobuloalveoli from ductal epithelium. Breast Cancer Research 8, 207.

Oganov VS, Baranov VS, Kabitskaia OE, Novikov VE, Bakulin AV, Moskalenko MV, Aseev MV, Voitulevich LV (2010) [Analysis of polymorphism of bone metabolism genes and evaluation of the risk of osteopenia in cosmonauts]. Aviakosm Ekolog Med 44, 1823.

Ohnishi T, Inoue N, Matsumoto H, Omatsu T, Ohira Y, Nagaoka S (1996) Cellular content of p53 protein in rat skin after exposure to the space environment. Journal of Applied Physiology (1985) 81 183-185.

Ohnishi T, Takahashi A, Wang X, Ohnishi K, Ohira Y, Nagaoka S (1999) Accumulation of a tumor suppressor p53 protein in rat muscle during a space flight. Mutation Research 430, 271-274.

Okaichi K, Suzuki K, Morita N, Ikeda M, Takahashi H, Matsuda N, Watanabe M, Okumura Y (2002) Low dose of wortmannin reduces radiosensitivity of human glioblastoma cells through the p53 pathway. Oncology Reports 9, 859-862.

Oren M (1999) Regulation of the p53 tumor suppressor protein. The Journal of Biological Chemistry 274, 36031-36034.

Patel OV, Maple RL, Baer LA, Ronca A, Wade CE, Plaut K (2007) Tissue-specific variation in expression of prolactin receptor gene subtypes in hypergravity-exposed rats. Journal of Gravitational Physiology 14, P129-P130.

Patel OV, Zakrzewska E, Maple RL, Baer LA, Ronca AE, Wade CE, Plaut K (2008) Lipogenesis impaired in periparturient rats exposed to altered gravity is independent of prolactin and glucocorticoid secretion. European Journal of Applied Physiology 104, 847-858.

Peehl DM, Skowronski RJ, Leung GK, Wong ST, Stamey TA, Feldman D (1994) Antiproliferative effects of 1,25-dihydroxyvitamin D3 on primary cultures of human prostatic cells. Cancer Research 54, 805-810.

Pu X, Storr SJ, Zhang Y, Rakha EA, Green AR, Ellis IO, Martin SG (2017) Caspase-3 and caspase-8 expression in breast cancer: Caspase-3 is associated with survival. Apoptosis 22, 357-368.

Sarkar D, Nagaya T, Koga K, Kambe F, Nomura Y, Seo H (2000) Rotation in clinostat results in apoptosis of osteoblastic ROS 17/2.8 cells. Journal of Gravitational Physiology 7, P71-P72.

Shikone T, Kokawa K, Yamoto M, Nakano R (1997) Apoptosis of human ovary and uterine endometrium during the menstrual cycle. Hormone Research 48 Suppl 3, 27-34.

Sibonga JD (2013) Spaceflight-induced bone loss: Is there an osteoporosis risk? Current Osteoporosis Reports 11, 92-98.

Smith SM, Heer M (2002) Calcium and bone metabolism during space flight. Nutrition 18, 849-852.

Smith SM, Wastney ME, Morukov BV, Larina IM, Nyquist LE, Abrams SA, Taran EN, Shih CY, Nillen JL, Davis-Street JE, Rice BL, Lane HW (1999) Calcium metabolism before, during, and after a 3-mo spaceflight: Kinetic and biochemical changes. American Journal of Physiology 277, R1-R10.

Smith SM, Wastney ME, O'Brien KO, Morukov BV, Larina IM, Abrams SA, Davis-Street JE, Oganov V, Shackelford LC (2005) Bone markers, calcium metabolism, and calcium kinetics during extended-duration space flight on the mir space station. Journal of Bone and Mineral Research 20, 208-218.

Streichan SJ, Hoerner CR, Schneidt T, Holzer D, Hufnagel L (2014) Spatial constraints control cell proliferation in tissues. Proceedings of the National Academy of Sciences of the USA 111, 5586-5591.

Tian Y, Ma X, Yang C, Su P, Yin C, Qian AR (2017) The impact of oxidative stress on the bone system in response to the space 
special environment. International Journal of Molecular Sciences 18, pii: E2132.

Uva BM, Masini MA, Sturla M, Prato P, Passalacqua M, Giuliani M, Tagliafierro G, Strollo F (2002) Clinorotation-induced weightlessness influences the cytoskeleton of glial cells in culture. Brain Research 934, 132-139.

Wehland M, Ma X, Braun M, Hauslage J, Hemmersbach R, Bauer J, Grosse J, Infanger M, Grimm D (2013) The impact of altered gravity and vibration on endothelial cells during a parabolic flight. Cellular Physiology and Biochemistry 31, 432-451.

Werneck-Silva AL, Alvares EP, Gama P, Damiao AO, Osaki LH, Ogias D, Sipahi AM (2006) Intestinal damage in strongyloidiasis: The imbalance between cell death and proliferation. Digestive Diseases and Sciences 51, 1063-1069.

Winter RN, Kramer A, Borkowski A, Kyprianou N (2001) Loss of caspase-1 and caspase-3 protein expression in human prostate cancer. Cancer Res 61, 1227-1232.

Xin M, Yang Y, Zhang D, Wang J, Chen S, Zhou D (2015) Attenuation of hind-limb suspension-induced bone loss by curcumin is associated with reduced oxidative stress and increased vitamin D receptor expression. Osteoporosis International 26, 2665-2676.

Yang H, Bhat GK, Sridaran R (2002) Clinostat rotation induces apoptosis in luteal cells of the pregnant rat. Biology of Reproduction 66, 770-777.

Zanello SB, Theriot CA, Prospero-Ponce C, Chevez-Barrios P (2013) Spaceflight effects and molecular responses in the mouse eye: Preliminary observations after shuttle mission STS-133. Gravitational and Space Research 1, 29-46.

Zheng TS, Hunot S, Kuida K, Flavell RA (1999) Caspase knockouts: Matters of life and death. Cell Death \& Differentiation 6, 10431053.

Zimmermann KC, Bonzon C, Green DR (2001) The machinery of programmed cell death. Pharmacology \& Therapeutics 92, 57-70.

Zinser GM, Suckow M, Welsh J (2005) Vitamin D receptor (VDR) ablation alters carcinogen-induced tumorigenesis in mammary gland, epidermis and lymphoid tissues. The Journal of Steroid Biochemistry and Molecular Biology 97, 153-164.

Zinser GM, Welsh J (2004a)Accelerated mammary gland development during pregnancy and delayed postlactational involution in vitamin D3 receptor null mice. Molecular Endocrinology 18, 2208-2223.

Zinser GM, Welsh J (2004b) Vitamin D receptor status alters mammary gland morphology and tumorigenesis in MMTV-neu mice. Carcinogenesis 25, 2361-2372. 